\title{
Optical and electrical properties of Ti-doped In203 film deposited on flexible transparent substrates by ion beam assisted deposition under different oxygen flow rate
}

Pakpoom Chansri ( $\square$ pakpoom.cha@kmutt.ac.th )

King Mongkut's University of Technology Thonburi https://orcid.org/0000-0003-4595-0926

\section{Pattarapon Pooyodying}

Department of Electrical Engineering, Rajamangala University of Technology Rattanakosin

\section{Youl Moon Sung}

Department of Electrical Engineering, Kyungsung University

\section{Article}

Keywords: titanium doped indium oxide, oxygen flow rate, ion beam-assisted deposition, flexible transparent substrates

Posted Date: August 23rd, 2021

DOl: https://doi.org/10.21203/rs.3.rs-833438/v1

License: (c) (1) This work is licensed under a Creative Commons Attribution 4.0 International License.

Read Full License 


\title{
Optical and electrical properties of Ti-doped $\operatorname{In}_{2} \mathrm{O}_{3}$ film deposited on flexible transparent substrates by ion beam assisted deposition under different oxygen flow rate
}

\author{
Pakpoom Chansri ${ }^{1, *}$, Pattarapon Pooyodying ${ }^{2}$ and Youl Moon Sung ${ }^{3}$ \\ ${ }^{1}$ Department of Electrical Technology Education, King Mongkut's University of Technology Thonburi, \\ Bangkok, 10140, Thailand \\ ${ }^{2}$ Department of Electrical Engineering, Rajamangala University of Technology Rattanakosin, \\ Nakhonpathom, 73170, THAILAND \\ ${ }^{3}$ Department of Electrical Engineering, Kyungsung University, Busan 608-736, Korea \\ *Corresponding Author: pakpoom.cha@kmutt.ac.th
}

\begin{abstract}
A flexible transparent is an important technology to improve flexible electronic and flexible display devices. Actually, the deposition process of films coated on a flexible substrate will no more than $200{ }^{\circ} \mathrm{C}$ or room temperature. In order to achieve high transmission and lower resistivity, this paper reported the thin films of ITiO deposited by ion beam-assisted electron beam under the condition of different oxygen flow rates at room temperature. The electrical, optical, and morphological properties of ITiO films were investigated under the condition of different oxygen flow rates. At the $30 \mathrm{sccm}$ oxygen flow rate, the surface roughness was $5.4 \mathrm{~nm}$, high transmittance and optical bandgap of ITiO films were $89.2 \%$ at 470 nm wavelengths and $3.28 \mathrm{eV}$, respectively. The lowest resistivity of film was $2.1 \times 10^{-4} \Omega-\mathrm{cm}$ at $30 \mathrm{sccm}$ oxygen flow rate. Furthermore, the carrier concentration and hall mobility were experimentally investigated, which presented by $42.8 \mathrm{~cm}^{2} / \mathrm{Vsec}$ and $9.23 \times 10^{20} \mathrm{~cm}^{-3}$. The use ITiO film coated on a flexible substrate with ion beam-assisted electron beam evaporation at room temperature can improve the
\end{abstract}


lower resistivity and high transmission of the flexible device. It was also demonstrated that ITiO film with ion beam-assisted deposition technique is suitable for flexible electronic and flexible display devices.

Keyword : titanium doped indium oxide, oxygen flow rate, ion beam-assisted deposition, flexible transparent substrates 


\section{Introduction}

The most common flexible display and flexible electronics devices are basically developed by transparent conducting oxide (TCO). The oxide materials are useful in allowing the device to coat on polyethylene terephthalate (PET) substrate, which can be bent into various shapes such as indium tin oxide (ITO), indium zinc oxide (IZO), and aluminum indium zinc oxide (AIZO) ${ }^{1-3}$. These materials oxides are semiconductors, which has a wide band gap, there are also other advantages including good insulators, transparent electronics, and photonics. These oxide materials have been widely used in many flexible devices, for instance, flexible solar cells, electroluminescence (EL), thin film transistors (TFT) and others ${ }^{4-6}$.

Indium oxide or Indium (III) oxide $\left(\operatorname{In}_{2} \mathrm{O}_{3}\right)$ is the one of the oxide materials that is used as a precursor to doping agents due to its several advantages like does not oxidation with water, it is heat resistant when mixed with non-metals and metals, good electrical conductivity, low resistivity, high visible light transmission, UV absorption reflects more infrared reflections, wear resistant, and chemical corrosion ${ }^{7,8}$. However, there are some disadvantages such as high-cost, poor electrical conductivity and also can create problem like toxic. To address these problems, it can be improved by adding titanium dioxide $\left(\mathrm{TiO}_{2}\right)$ doped indium oxide (ITiO). Because, it offers more effective like low resistance sheet properties. In addition, the transmission of ITiO film is near-infrared. The properties of the ITiO layer show that the wavelength is $1500 \mathrm{~nm}$ when compared to $1000 \mathrm{~nm}$ for a resistance sheet of $8 \mathrm{ohm} / \mathrm{sq}^{9-12}$.

According to previous studies, the direct current (DC) and radio frequency (RF) magnetron sputtering were particularly used to be the coating process of ITO. In the coating process, oxygen must be controlled because ineffective control has directly affected to the coating layer, may not adhere well. Especially, the controlled pressure is poorly controlled, 
which has a negative effect to the adhesion-related on surface. For solving the problems, the ion beam-assisted process is use, which can be controlled the oxygen flow rate resulting in hardness and the coefficient of friction accumulates is decreased. Consequently, it has enhanced adhesion when using ion beam-assisted techniques ${ }^{13,14}$. For this reason, we are focusing on the ion beamassisted technique for ITiO film-coated PET substrates, which could be enhanced properties of transmittance and lower resistivity.

This paper proposes a titanium doped indium oxide film coated on the surface of PET by ion beam-assisted techniques at room temperature. The structural, electrical, and optical properties of deposited ITiO films on PET substrate by ion beam-assisted deposition at room temperature on different oxygen flow rate conditions were investigated. The conditions of ITiO films by ion beam-assisted process are significant to performance flexible transparent substrates.

\section{Experimental Setup}

As previous studied, the preparation of ion beam-assisted deposition process was reported 15,16. The resistive sources were conducted by turbo-pumped coating chamber at 6 -pocket $270^{\circ}$. The electron beam gun was controlled under $14 \mathrm{~kW}$ with a quartz crystal rate/thickness. The ion source by Kaufman \& Robinson, Inc. was placed in coating chamber, as seen in Fig. 1. The evaporation source material of ion beam-assisted deposition system was used $10 \%$ titanium dioxide ( Aldrich) with $99.99 \%$ of purity. The pressure of evaporation was $\sim 4 \times 10^{-3}$ mtorr at room temperature. The quartz crystal monitor was monitored for evaporation rate and thickness of 
film. In during the deposition process, ion energy and ion current density was controlled at 160 $\mathrm{eV}$ and $100 \mu \mathrm{A} / \mathrm{cm}^{2}$, respectively.

The PET substrates were cleaned by ultrasonic washer with acetone at $45 \mathrm{~min}$, alcohol at $45 \mathrm{~min}$, the organic compounds was removed by de-ionized water, and after that was blow dried with nitrogen gas. The obtained PET substrates were coated with ITiO by ion beam-assisted on the condition of oxygen flow rate at 10,20 and $30 \mathrm{sccm}$. The flow rate was determined by a mass flow controller (MKS). The electrical and optical properties of ITiO film were measured by a sheet resistance meter (Dasol Eng; FPP-HS8), hall-effect measurements (ECOPIA HMS-5000) and UV spectrophotometer (Hitachi; U-3900) the structure of film was investigated by atomic force microscopy (AFM) (WITec GmbH;alpha300 RA) and X-ray diffractometer (XRD) (Rigaku; D/max 2100H) under $\mathrm{Cu}$ Ka irradiation $(\lambda=1: 5418 \AA)$

\section{Result and Discussion}

The structure, electrical and optical properties of ITiO films deposited on flexible (PET) substrate by ion beam-assisted deposition were controlled with an oxygen flow rate range of 10 , 20, and $30 \mathrm{sccm}$. The deposition rate in all films was deposited at $200 \mathrm{~nm}$ of thickness, 0.5 $\mathrm{nm} / \mathrm{sec}$ rate of deposition, $160 \mathrm{eV}$ of ion energy and $100 \mu \mathrm{A} / \mathrm{cm}^{2}$ of ion current density.

Fig. 2 shows the X-ray diffraction (XRD) pattern of ITiO films deposited on flexible (PET) substrate by ion beam-assisted deposition. As can be seen in Fig. 2, the strong peak of all films has corresponded $\operatorname{In}_{2} \mathrm{O}_{3}(222)$ plane at $35.05^{\circ}(2 \theta)$ and $\mathrm{Ti}(101)$ plane at $25.62^{\circ}(2 \theta)$. All peaks of (400), (440), and (622) planes were found in agreement with $\mathrm{In}_{2} \mathrm{O}_{3}$ and $\mathrm{TiO}_{2}$ planes were not found as extra peaks. However, $\mathrm{TiO}_{2}$ doped indium oxide resulted in slow cumulative 
growth of grain size in indium. From previous reports ${ }^{17-24}$, the amount of ion energy and ion current density was obtained from the positive ions colliding to target will increase with increasing oxygen flow rate. The energy of ions was dependent on the oxygen flow rate, electrons are released from the replacement of $\operatorname{In}_{2} \mathrm{O}_{3}$ atoms cause charged oxygen vacancies. Oxygen vacancies can increase the double charge of oxygen. The existence of $\mathrm{TiO}_{2}$ will result in $n$ doping of the lattice due to the doped materials that would be increased electrons to the conduction band ${ }^{25-27}$.

In order to confirm the effect of oxygen flow rates on the structural properties of the ITiO films by ion beam-assisted deposition, the AFM of the ITiO films deposited at different oxygen flow rates at 10 to $30 \mathrm{sccm}$ were investigated. Fig. 3 shows the AFM of the ITiO films deposited on flexible (PET) substrate by ion beam-assisted deposition. As the oxygen flow rates increase up to $30 \mathrm{sccm}$, the crystallite size of the ITiO films at $10 \mathrm{sccm}$ of oxygen flow rate was less than that $30 \mathrm{sccm}$ of oxygen flow rate. Increasing the oxygen flow rate excites crystal growth and induces film crystallinity improvement. Moreover, AFM of the films has measured the roughness of the films, it depended on the fabrication parameters of the films. Normally, they use rootmean-square (RMS) evaluate to the roughness of the films. The root means square (RMS) uses the same classifying surfaces, RMS can be defined as the standard deviation of the surface height ${ }^{28}$. The root mean square (RMS) surface roughness of the ITiO films in all oxygen flow rates conditions was lower to $5.4 \mathrm{~nm}$ of RMS surface roughness. Increasing oxygen flow rates result in the mobility of the atom decrease, thereby providing rough thin films.

The detailed investigation of the transmittance (\%) of ITiO films deposited on flexible (PET) using ion beam assisted deposition was specially controlled with different oxygen flow rates, which was investigated by the UV-Visible spectrophotometer under the wavelength range 
300 to $800 \mathrm{~nm}$, as shown in Fig. 4. Obviously, the transmittance of the ITiO films in all oxygen flow rate conditions was shown by $84 \%$ over in the visible region. There have been found that the maximum transmittance value of ITiO films was presented by $89.2 \%$ under the oxygen flow rate of 30 seem with the wavelength of $470 \mathrm{~nm}$. Therefore, it can be summarized that the wavelengths of 450 to $500 \mathrm{~nm}$ are suitable for applying with a solar cell, comparing in all oxygen rate conditions. Note that because solar energy has a high intensity in the absorbance wavelength $450-550 \mathrm{~nm}$, which has a wavelength close to the film obtained ${ }^{29}$. In addition, when the oxygen flow rate is steadily increased, the absorption coefficient $(\alpha)$ of the film would be shifted onto the ultraviolet $(\mathrm{UV})(<350 \mathrm{~nm})$, which can be calculated by Lambert's formula ${ }^{11,12,16,30}$. In this point, it affects to the optical band gap values of the films.

$$
\alpha=\frac{1}{d} \ln \left(\frac{1}{T}\right)
$$

where $T$ and $d$ are transmittance and film thickness, respectively. In order to move to the conduction band, the energy level was defined by appropriate electron excitation and move to the conduction band. At low energy, the absorption can be grown with optical energy in the absorption edge of the semiconductors. The absorption coefficient is directly allowed to transit through a simple parabolic scheme form, which can be found a function of incident photon energy as follows:

$$
\alpha h v=A\left(h v-E_{g}\right)^{1 / 2}
$$

where $h v$ is photon energy and $E g$ is the optical band-gap.

The optical band-gap of ITiO films can be determined by means of extrapolation from $(\alpha h v)^{2}$ versus $h v$. As a continuously increased of oxygen flow rate, the optical energy band gap 
of $3.23 \mathrm{eV}$ to $3.28 \mathrm{eV}$ were found, as seen Fig. 5. Thus, the increasing of oxygen flow rate results the significant resistivity reduction and the visible range of films is fairly good transparency. The energy bandgap of ITiO films gives more energy to make a low wavelength range of the incident light. Note that the light transmittance of ITiO film is flowed through to the PET substrate under the condition of different wavelengths, where the titanium dioxide has an energy level larger than $3.2 \mathrm{eV}^{31-32}$.

The oxygen flow rates of ITiO films have an evident effect to the light transmittance range of films in the UV range. As can be seen in Fig. 6, the resistivity and sheet resistance of ITiO films deposited at $160 \mathrm{eV}$ of ion density under different conditions of oxygen flow rates was presented. Looking in more detail, there have been found that the lowest resistivity of the ITiO films was illustrated under the condition $30 \mathrm{sccm}$ of oxygen flow rate, which was presented by $2.1 \times 10^{-4} \Omega$-cm. In addition to this point, the resistivity at $10 \mathrm{sccm}$ and $20 \mathrm{sccm}$ of oxygen flow rates were nearly constant at $2.7 \times 10^{-4} \Omega$-cm and $2.6 \times 10^{-4} \Omega$-cm, respectively.

It is important to note that the decreased of resistivity is the result of rising in the oxygen flow rates because the deposition process has a sufficient oxidation of ITiO films, which may cause in the oxygen absorption in the grain boundaries. The sheet resistances of the ITiO films density under different oxygen flow rates were found that $34.1 \Omega / \mathrm{sq}, 32.6 \Omega / \mathrm{sq}$, and $28.6 \Omega / \mathrm{sq}$, respectively. It demonstrates that a minimum at $30 \mathrm{sccm}$ oxygen flow rate.

The increasing oxygen flow rate causes oxygen-deficient ITiO films. The increasing oxygen incorporation causes the oxygen-deficient of the film thus sheet resistance of ITiO film depends on oxygen vacancy into evaporated films ${ }^{16}$. At $30 \mathrm{sccm}$ oxygen flow rate, the resistivity and sheet resistance of films presented the lowest value because the oxygen was etched on 
surface area, which cause surface modification by ion beam-assisted process, as can be seen in Fig. 3. Moreover, it shows a jagged hole and a groove on the surface is decrease. The lower oxygen flow rates have importantly affect to the ITiO films, which cause to the surface have a free space and electron concentration will be increased ${ }^{33,34}$.

The hall mobility and carrier concentration and of ITiO thin films by deposited on flexible substrate by ion beam-assisted deposition under different oxygen flow rates, as seen in Fig. 7. The hall mobility was slightly enhanced $36.2-42.8 \mathrm{~cm}^{2} / \mathrm{Vsec}$ with increasing oxygen flow rates from 10 to $30 \mathrm{sccm}$. As can be seen, the highest mobility was located by $30 \mathrm{sccm}$ of oxygen flow rate about $42.8 \mathrm{~cm}^{2} / \mathrm{Vsec}$. At low resistivity and sheet resistance of films result a high hall mobility because it attributed to a formation of $\operatorname{In}_{2} \mathrm{O}_{3}$ in the films. Thus, the electrons or ions are released from the replacing to indium (In) atom in the sublattice, and from oxygen vacancies with double charge ${ }^{26,35}$. The carrier concentration of ITiO film under different oxygen flow rate has reached the peak of $1.12 \times 10^{21} \mathrm{~cm}^{-3}$ under oxygen flow rate $10 \mathrm{sccm}$ and reduced to $9.23 \times 10^{20} \mathrm{~cm}^{-3}$ under oxygen flow rate $30 \mathrm{sccm}$. When, the rising oxygen flow rate result increase carrier concentration. The on energy and ion density will cause kinetic energy move to the condition band ${ }^{36,37}$. Moreover, the relationship between electrical resistivity and carrier concentration could be explained by the morphological properties of the film with AFM morphology in Fig. 3. It was confirmed that the rising oxygen flow rate could not grow crystalline grains that was observed from the porosity on the surface. The increasing oxygen flow rate results in a decrease grain size, thereby reducing resistivity, increased mobility, and increased concentration. 


\section{Conclusions}

The effect of ITiO films coated on the surface of PET by ion beam-assisted techniques at room temperature under different oxygen flow rates. During the deposition process, $160 \mathrm{eV}$ of ion energy, $100 \mu \mathrm{A} / \mathrm{cm}^{2}$ of on density, $100 \mathrm{~nm}$ of thickness, and $0.5 \mathrm{~nm} / \mathrm{sec}$ of deposition rates were experimentally used. In an experiment, the lowest resistivity of ITiO film was $2.1 \times 10^{-4} \Omega$-cm at $30 \mathrm{sccm}$ of oxygen flow rate. The optical transmittance and optical band-gap of ITiO film were $89.2 \%(470 \mathrm{~nm})$ and $3.28 \mathrm{eV}$ under $30 \mathrm{sccm}$ of oxygen flow rate. The hall mobility and carrier concentration of ITiO film were $42.8 \mathrm{~cm}^{2} / \mathrm{Vsec}$ and $9.23 \times 10^{20} \mathrm{~cm}^{-3}$ at $30 \mathrm{sccm}$ of oxygen flow rate, respectively. According to these results, under oxygen flow rates at ion energy and ion density constant are attractive methods to produce a high-quality ITiO film which is a suitable 30 sccm oxygen flow rate. The use ion beam-assisted techniques under different oxygen flow rates can improve the crystalline and electrical properties of ITiO film on PET substrate.

\section{Acknowledgements}

This work was supported by King Mongkut's University of Technology Thonburi (KMUTT), Thailand, under the project of the National Research University Project of Thailand's Office of the Higher Education Commission for financial support. 


\section{Reference}

[1] Park, H. J., Kim, J., Won J. H., Choi, K. S., Lim, Y. T., Shin, J. S., \& Park, J. U. Tin-doped indium oxide films for highly flexible transparent conducting electrodes. Thin Solid Films. 615, 8-12 (2016).

[2] Heo, S. W., Lee, E. J., Han, Y. W., Lee, Y. S., Lee, W. J., Choa, S. H., Kim, Y. S., \& Moo,

D. K. Improved performance of flexible polymer light emitting diodes with an indium-zinc-tinoxide transparent anode by controlling the thermal treatment temperature. J Indus Eng Chem. 53, 68-76 (2017).

[3] Poonthong, W., Chansri P., Mungkung, N., Arunrungrusmi, S., Sung, Y. M., \& Yuji, T. Characterization analysis of aluminum and indium codoping zinc oxide on flexible transparent substrates by rf magnetron sputtering process. IEEE Trans Plasma Sci. 48(11), 3921 - 3927 (2020).

[4] Liu, H., Wu, J., Fu, Y., Wang, B., Yang, Q., Sharma, G. D., Keshtov, M. L., \& Xie, Z. Onestep solution-processed low surface roughness silver nanowire composite transparent electrode for efficient flexible indium tin oxide-free polymer solar cells. Thin Solid Films. 718, 138486 (2021).

[5] Chansri, P., Arunrungrusmi, S., Yuji, T., \& Mungkung, N. An analysis of ZnS:Cu phosphor layer thickness influence on electroluminescence device performances. Inter $J$ Photoenergy. 2017, Article ID 6752984 (2017).

[6] Vidor, F. F., Meyers, T., Wirth, G. I., \& Hilleringmann U. ZnO nanoparticle thin-film transistors on flexible substrate using spray-coating technique. Microelectronic Eng. 159, 155158 (2016). 
[7] Wen, A.J.C., Chen, K.L., Yang, M. H., Hsiao, W.T., Chao, L.G., \& Leu, M.S. Effect of substrate angle on properties of ITO films deposited by cathodic arc ion plating with In-Sn alloy target" Surf Coat Technol. 198, 362-366 (2005).

[8] Tang, Q., Zhou, W., Zhang, W., Ou, S., Jiang, K., Yu, W., \& Qian, Y. Size-controllable growth of single crystal $\mathrm{In}(\mathrm{OH})_{3}$ and $\mathrm{In}_{2} \mathrm{O}_{3}$ nanocubes. Crystal Growth \& Design 5(1), 147-150 (2005).

[9] Heo, J. H., Jung, K. Y., Kwak, D. J., Lee, D. K., \& Sung, Y. M. Fabrication of titaniumdoped indium oxide films for dye - sensitized solar cell application using reactive RF Magnetron Sputtering Method. IEEE Trans Plasma Sci, 37, 1586-1592 (2009).

[10] Yan, L.Y. \& Schropp R.E.I., Changes in the structural and electrical properties of vacuum post-annealed tungsten- and titanium-doped indium oxide films deposited by radio frequency magnetron sputtering Thin Solid Films. 520, 2096-2101 (2012).

[11] Chaoumead, A., Joo, B. H., Kwak, D. J., Sung, Y. M. Structural and electrilal prpperties of sputtering power and gas pressure on Ti-dope $\ln _{2} \mathrm{O}_{3}$ transparent conductive films by RF magnetron sputtering. Appl Surf Sci. 275, 227-232 (2013).

[12] W. Poonthong, N. MungKung, P. Chansri, S. Arunrugrusni, \& Yuji, T. Performance analysis of Ti-doped $\mathrm{In}_{2} \mathrm{O}_{3}$ thin films prepared by various doping concentations using $\mathrm{RF}$ magnetron sputtering for light-emitting device. Inter J Photoenergy. 2020, article ID 8823439 (2020).

[13] Martin, P. J., Macleod, H. A., Netterfield, R. P., Pacey, C, G., \& Sainty, W. G. Ion-beamassisted deposition of thin films. Appl Opt. 22(1), 178-84 (1983). 
[14] Ensinger, W., Schröer, G., \& Wolf, K. Are coatings produced by ion-beam-assisted deposition superior? A comparison of chemical and mechanical properties of steel coated using different deposition techniques, Surf Coat Technol. 51, 217-222 (1992).

[15] Ensinger, W. Ion sources for ion beam assisted thin-film deposition. Rev Sci Instrum. 63(11), 5217-5233 (1992).

[16] Farhan, M. S., Zalnezhad, E., Bushroa, A. R., \& Sarhan, A. A. D. Electrical and optical properties of indium-tin oxide (ITO) films by ion beam-assisted deposition (IAD) at room temperature, Int J Precis Eng Manuf. 14(8) 1465-1469 (2013).

[17] Youn J. Kim, Su B. Jin, Sung I. Kim, Yoon S. Choi, In S. Choi, Jeon G. Han, "Effect of oxygen flow rate on ITO thin films deposited by facing targets sputtering" Thin Solid Films. 518(22), 6241-6244 (2010).

[18] Meng, L.J., Gao, J., Silva, R.A., \& Song, S. Effect of the oxygen flow on the properties of ITO thin films deposited by ion beam assisted deposition (IBAD). Thin Solid Films. 516(16), 5454-5459 (2008).

[19] Meng, L.J., Gao, J., M.P.D Santos, M.P.D, X. Wang, X., \& Wang, T. The effect of the ion beam energy on the properties of indium tin oxide thin films prepared by ion beam assisted deposition. Thin Solid Films. 516(7), 1365-1369 (2008).

[20] Zhinong, Y., Yuqiong, L., Fan, X., Zhiwei, Z., \& Wei, X. Properties of indium tin oxide films deposited on unheated polymer substrates by ion beam assisted deposition. Thin Solid Films 517(18), (2009), 5395-5398 (2009). 
[21] Pokaipisit, A., Horprathum, M., \& Limsuwan, P. Influence of oxygen flow rate on properties of indium tin oxide thin films prepared by ion beam-assisted electron beam evaporation. Songklanakarin J Sci Technol. 31(5), 577-581 (2009).

[22] Kuo, C.C., Liu, C.C., Lin, C.C., Liou, Y.Y., Lan, Y.F., \& He, J.L. Effects of oxygen flow rate on microstructure and properties of indium molybdenum oxide films by ion beam-assisted deposition. Vacuum. 82(5), $441-447$ (2008).

[23] Chiu, P., Liao, Y. T., Tsai, H. Y., \& Chiang, D. Effect of electron-beam deposition process variables on the film characteristics of the CrOx films. AIP Advances. 8(2), Article ID 025016. (2018).

[24] Zhang, Q.Y., Zhao, W.J., Wang, P.S., Wang, L., Xu, J.J., \& Chu, P.K. Microstructure, morphology and their annealing behaviors of alumina films synthesized by ion beam assisted deposition. Nucl Instrum Methods Phys Res B. 206, 357-361 (2003).

[25] Tien, C. L., Lin, H.Y., Chang, C. K., \& Tang, C. J., effect of oxygen flow rate on the optical, electrical, and mechanical properties of de sputtering ITO thin films. Adv Cond Matt Phys. 2018, Article ID 2647282 (2018).

[26] Meng, L. J., Маспаrico, A., \& Martins, R., Study of annealed indium tin oxide films prepared by $\mathrm{rf}$ reactive magnetron sputtering. Vacuum. 46(7), 673-680 (1995).

[27] Démarest, N., Deubel, D., Keromnès, J. C., Vaudry, C., Grasset, F., Lefort, R., \& Maryline G. V. Optimization of bandpass optical filters based on $\mathrm{TiO}_{2}$ nanolayers. Optical Eng. 54(1), Article ID 015101. (2015). 
[28] Bhushan, B. Surface Roughness Analysis and Measurement Techniques, Modern Tribology Handbook. (CRC Press LLC: Boca Raton, FL, USA, 2001).

[29] Krus, O., Rupprecht, J., Mussgnug, J.H., Dismukes, G. C., \& Hankamer, B. Photosynthesis: a blueprint for solar energy capture and biohydrogen production technologies. Photochem Photobiol Sci. 4(12), 957-970 (2006).

[30] Poonthong, W., Chansri, P., Mungkung, N., Arunrungrusmi, S., Sung, Y. M., \& Yuji, T. Characterization analysis of aluminum and indium codoping zinc oxide on flexible transparent substrates by rf magnetron sputtering process. IEEE Trans Plasma Sci. 48(11), 3921-3927 (2020).

[31] Valencia, S., Marín J. M., \& Restrepo, G. Study of the bandgap of synthesized titanium dioxide nanoparticules using the sol-gel method and a hydrothermal treatment" Open Mater Sci. 4, 9-14 (2010)

[32] Ansari, S., \& Cho, M. Highly visible light responsive, narrow band gap tio ${ }_{2}$ nanoparticles modified by elemental red phosphorus for photocatalysis and photoelectrochemical applications. Sci Rep. 6, 25405 (2016).

[33] Park, Y. S., Kim, E. K., Hong B. Y., \& Lee, J. H. Characteristics of ITO films with oxygen plasma treatment for thin film solar cell applications. Mater Res Bull. 48, 5115-5120 (2013).

[34] Arunrungrusmi, S., Chansri P. \& Mungkung, N. Transparent ITiO film electrodes on polyethylene terephthalate by oxygen plasma treatment for high-performance flexible electroluminescence device. Jpn J Appl Phys. 58(SA), SAAB02 (2019). 
[35] Grew, B., Bowers, J.W., Liso, F., Arnou, N., Walls, J.M., Upadhyaya, H.M. "High mobilty titamium-doped indium oxide for use tandem solar cell depositon via plused DC magnetron sputtering" Energy Procedia, 60, 148-155 (2014).

[36] Kim, H., Gilmore, C. M., Piqu'e A., Horwitz, J. S., Mattoussi, H., Murata, H., Kafafi, Z. H., \& Chrisey, D. B. Electrical, optical, and structural properties of indium-tin-oxide thin films for organic light-emitting devices. J Appl Phys. 86(11), 6451-6461 (1999).

[37] Pujar, P., Vardhan, R., Guta, D., Mandal, S. A balancing between super transparency and conductivity of solution combustion derived titanium doped indium oxide: Effect of charge carrier density and mobility. Thin Solid Films. 660, 267-275 (2018). 
Figure and Table

Fig. 1 Schematic diagram of ion beam-assisted deposition system.

Fig. 2 X-ray diffraction (XRD) pattern of ITiO films deposited on flexible (PET) substrate by ion beam-assisted deposition at 10, 20 and $30 \mathrm{sccm}$ oxygen flow rates.

Fig. 3 AFM of ITiO films deposited on flexible (PET) substrate by ion beam-assisted deposition at 10,20 and 30 sccm oxygen flow rates.

Fig. 4 Transmittance spectra of ITiO films by deposited on flexible (PET) substrate by ion beamassisted deposition under different oxygen flow rates at 10, 20 and $30 \mathrm{sccm}$.

Fig. 5 Energy bandgap of ITiO thin films by deposited on flexible (PET) substrate by ion beam-assisted deposition under different oxygen flow rates at 10, 20 and $30 \mathrm{sccm}$.

Fig. 6 Resistivity and sheet resistance of ITiO thin films by deposited on flexible (PET) substrate by ion beam-assisted deposition under different oxygen flow rates at 10, 20 and $30 \mathrm{sccm}$.

Fig. 7 Hall mobility and carrier concentration of ITiO thin films by deposited on flexible (PET) substrate by ion beam-assisted deposition under different oxygen flow rates at 10, 20 and $30 \mathrm{sccm}$. 


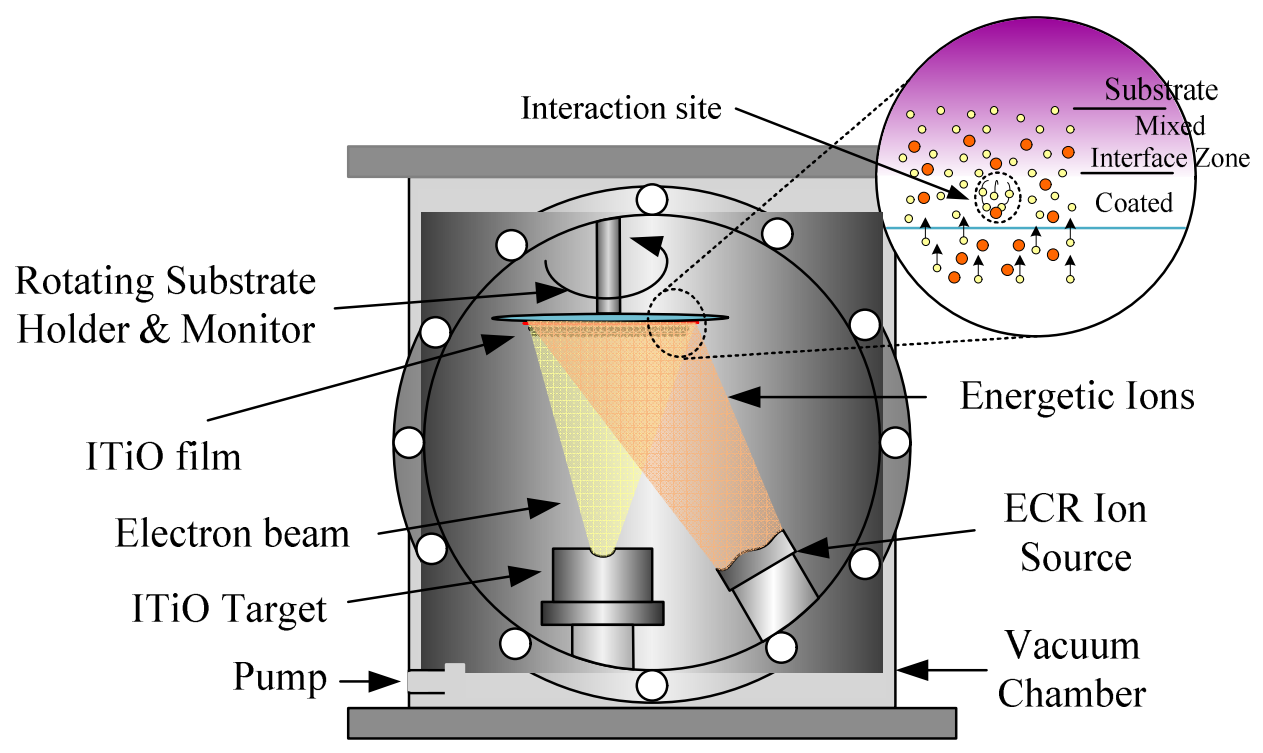

Fig. 1 Schematic diagram of ion beam-assisted deposition system. 


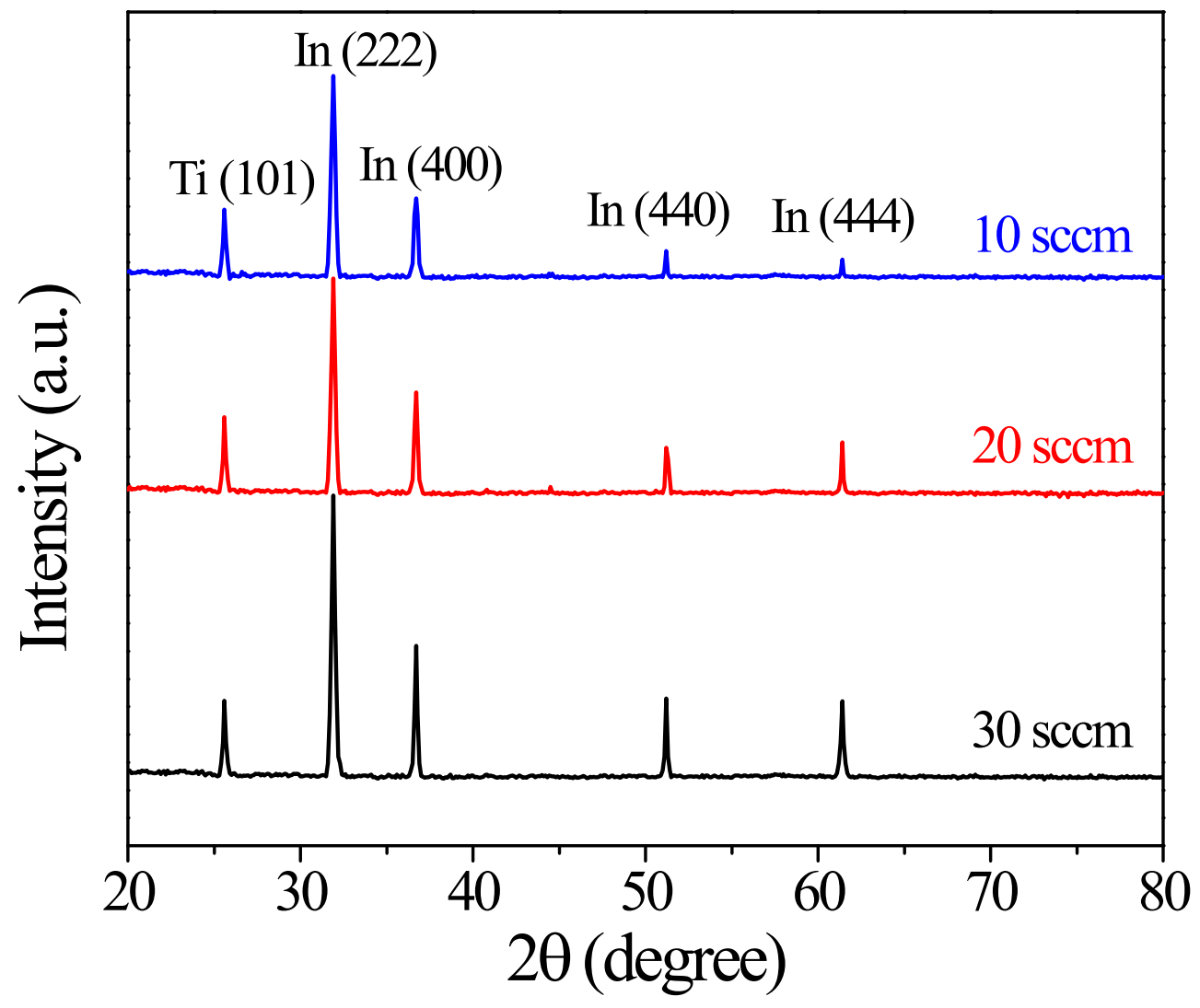

Fig. 2 X-ray diffraction (XRD) pattern of ITiO films deposited on flexible (PET) substrate by ion beam-assisted deposition at 10, 20 and $30 \mathrm{sccm}$ oxygen flow rates. 

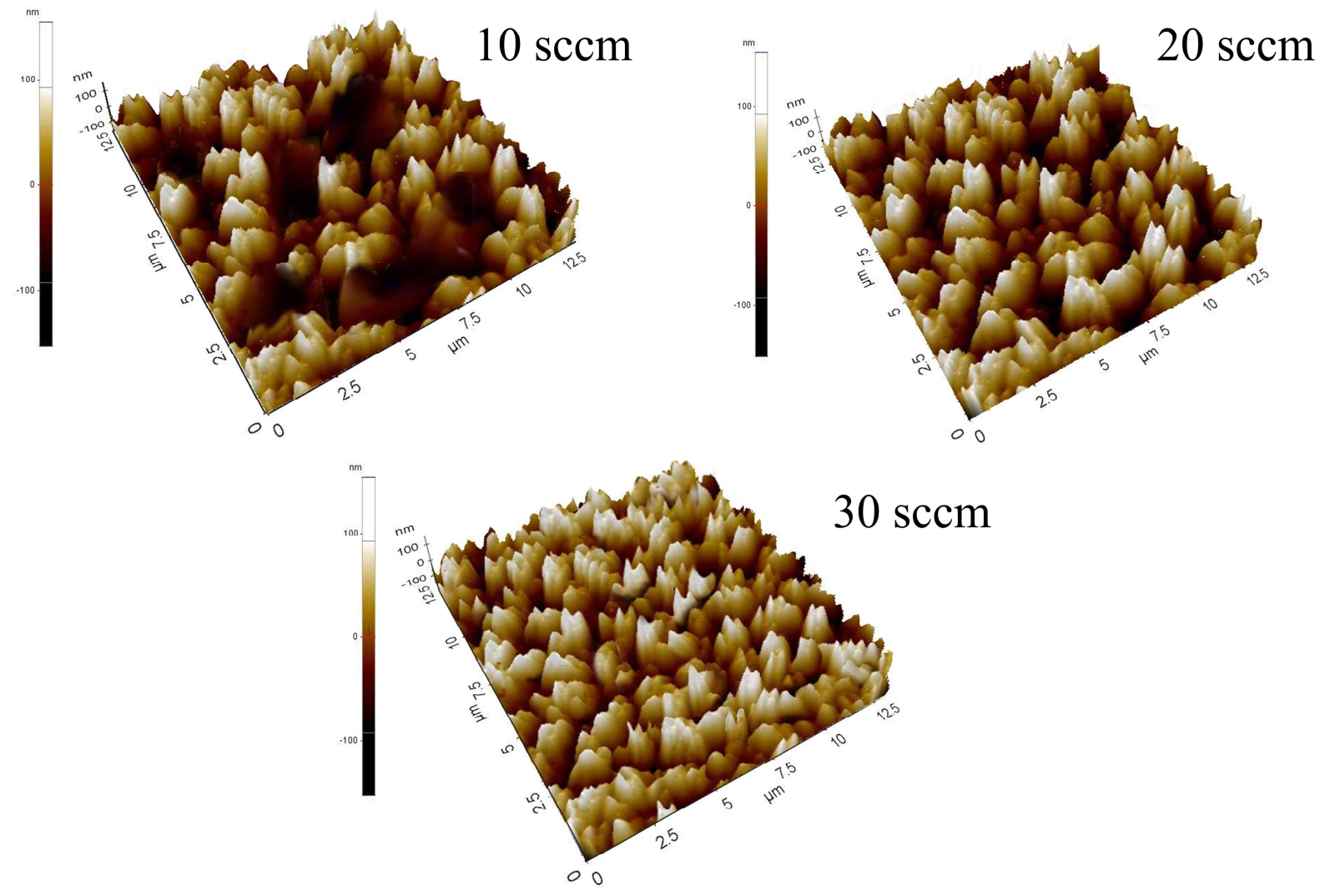

Fig. 3 AFM of ITiO films deposited on flexible (PET) substrate by ion beam-assisted deposition at 10,20 and $30 \mathrm{sccm}$ oxygen flow rates. 


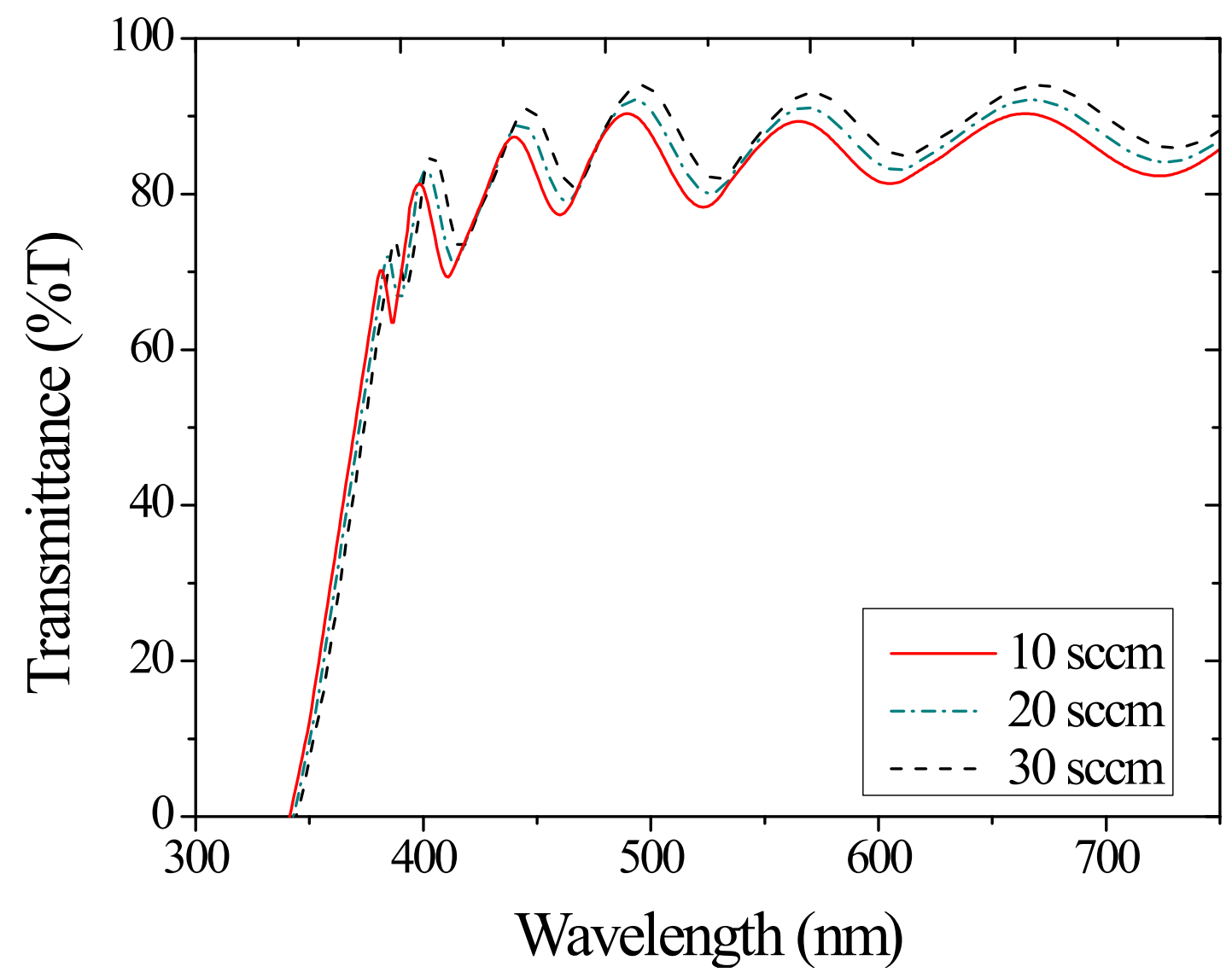

Fig. 4. Transmittance spectra of ITiO films by deposited on flexible (PET) substrate by ion beam-assisted deposition under different oxygen flow rates at 10, 20 and $30 \mathrm{sccm}$. 


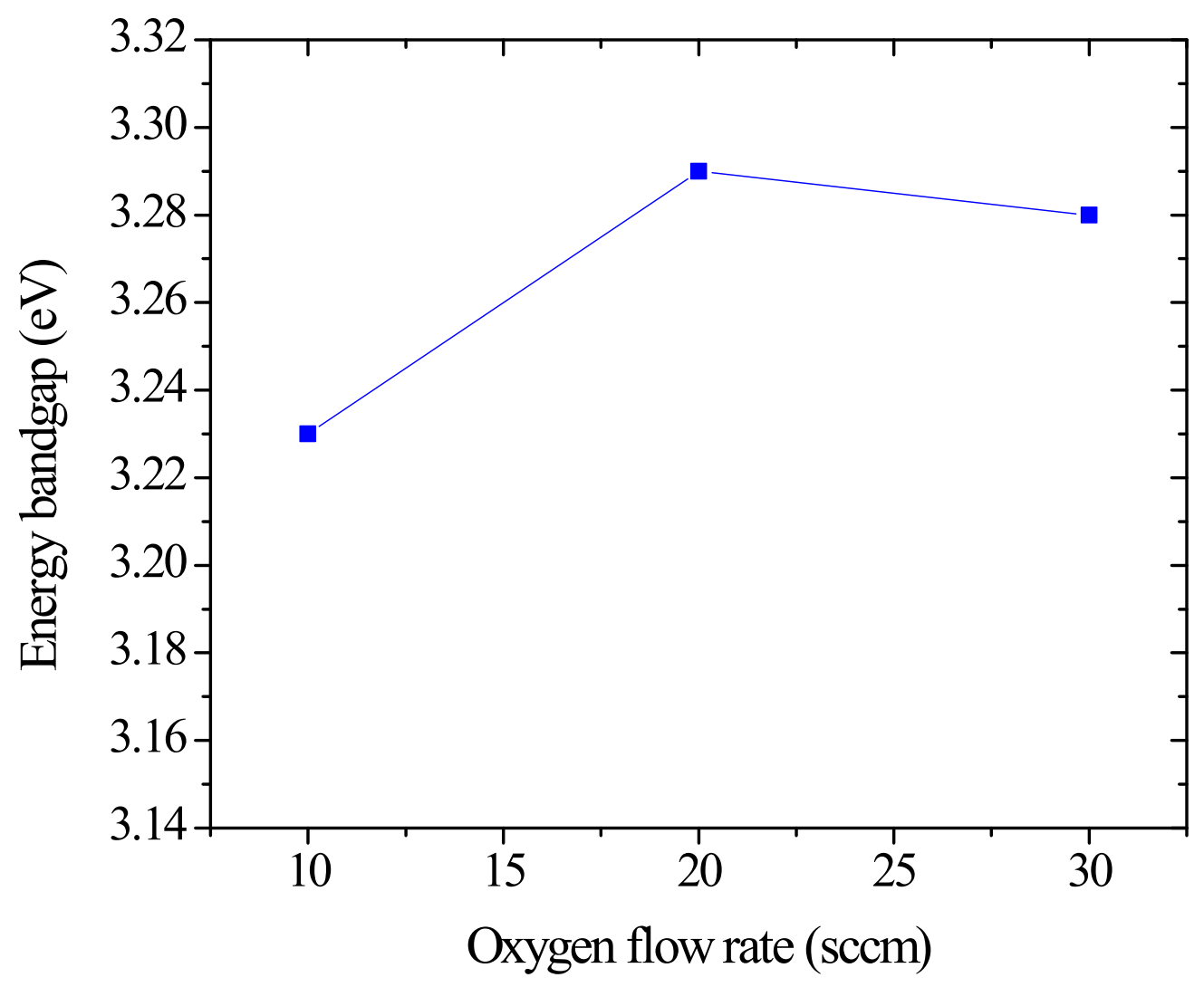

Fig. 5 Energy bandgap of ITiO thin films by deposited on flexible (PET) substrate by ion beam-assisted deposition under different oxygen flow rates at 10, 20 and $30 \mathrm{sccm}$. 


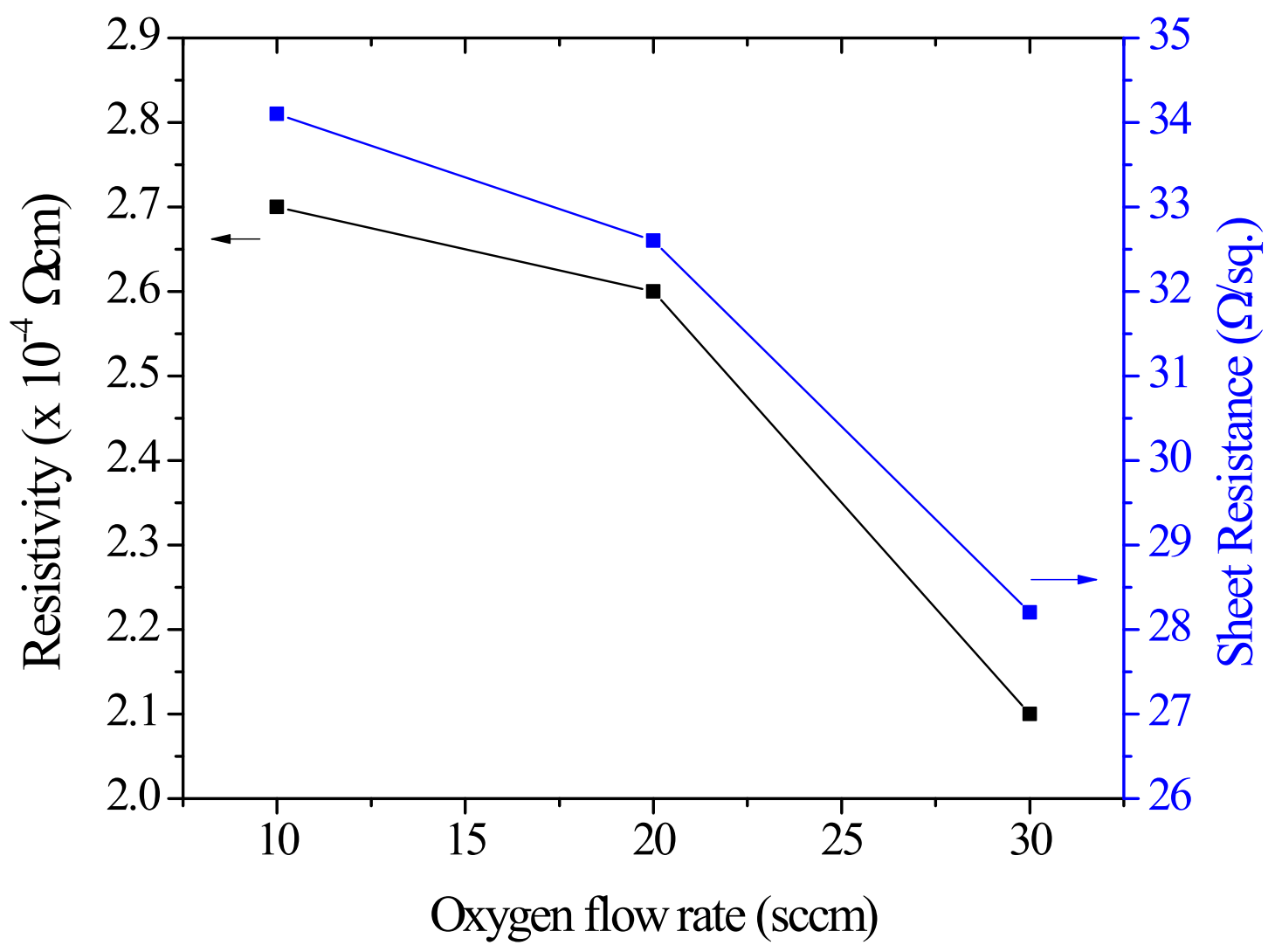

Fig. 6 Resistivity and sheet resistance of ITiO thin films by deposited on flexible (PET) substrate by ion beam-assisted deposition under different oxygen flow rates at 10, 20 and $30 \mathrm{sccm}$. 


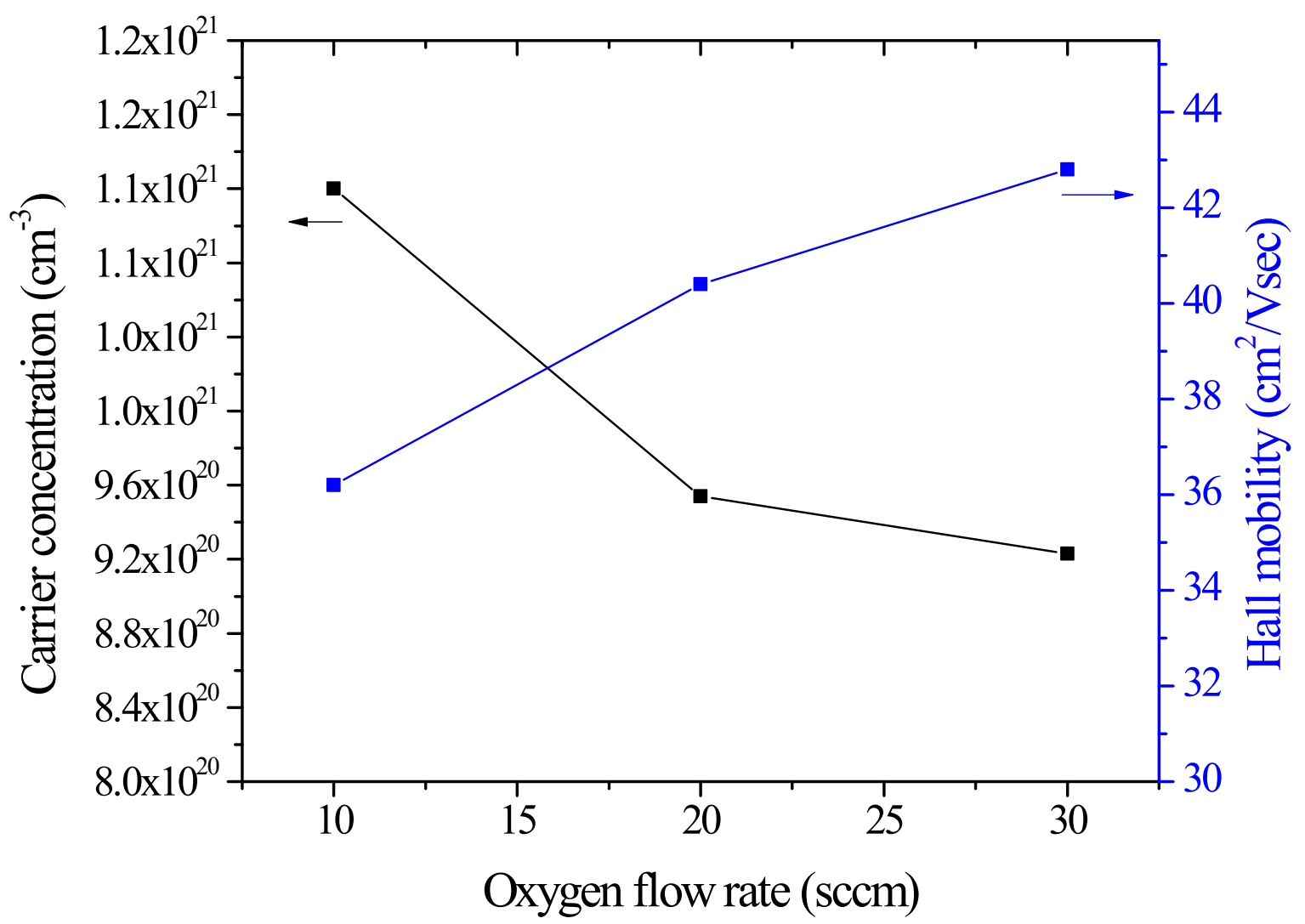

Fig. 7 Hall mobility and carrier concentration of ITiO thin films by deposited on flexible (PET) substrate by ion beam-assisted deposition under different oxygen flow rates at 10, 20 and $30 \mathrm{sccm}$. 